\title{
Dilute Surfactant Methods for Carbonate Formations
}

ID Number: DE-FC26-02NT 15322

Quarterly Progress Report

Reporting Period Start Date: 1-1-2005

Reporting Period End Date: 3-31-2005

Submitted to the

U.S. Department of Energy

Kishore K. Mohanty

Department of Chemical Engineering

University of Houston

4800 Calhoun Road

Houston, Texas 77204-4004

April, 2005 


\section{Disclaimer}

This report was prepared as an account of work sponsored by an agency of the United States Government. Neither the United States Government nor any agency thereof, nor any of their employees, makes any warranty, express or implied, or assumes any legal liability or responsibility for the accuracy, completeness, or usefulness of any information, apparatus, or process disclosed, or represents that its use would not infringe privately owned rights. Reference herein to any specific commercial product, process, or service by trade name, trademark, manufacturer, or otherwise does not necessarily constitute or imply its endorsement, recommendation, or favoring by the United States Government or any agency thereof. The views and opinions of authors expressed herein do not necessarily state or reflect those of the United States Government or any agency thereof. 


\begin{abstract}
There are many carbonate reservoirs in US (and the world) with light oil and fracture pressure below its minimum miscibility pressure (or reservoir may be naturally fractured). Many carbonate reservoirs are naturally fractured. Waterflooding is effective in fractured reservoirs, if the formation is water-wet. Many fractured carbonate reservoirs, however, are mixed-wet and recoveries with conventional methods are low (less than 10\%). Thermal and miscible tertiary recovery techniques are not effective in these reservoirs. Surfactant flooding (or huff-n-puff) is the only hope, yet it was developed for sandstone reservoirs in the past. The goal of this research is to evaluate dilute (hence relatively inexpensive) surfactant methods for carbonate formations and identify conditions under which they can be effective. Laboratory imbibition tests show about $61 \%$ oil recovery in the case of Alf-38 and $37 \%$ in the case of DTAB. A numerical model has been developed that fits the rate of imbibition of the laboratory experiment. Field-scale fracture block simulation shows that as the fracture spacing increases, so does the time of recovery. Plans for the next quarter include simulation studies.
\end{abstract}




\section{TABLE OF CONTENTS}

Page

Cover Page $\quad 1$

Disclaimer 2

$\begin{array}{ll}\text { Abstract } & 3\end{array}$

Table of Contents $\quad 4$

$\begin{array}{ll}\text { Executive Summary } & 6\end{array}$

$\begin{array}{ll}\text { Introduction } & 7\end{array}$

Experimental $\quad 8$

Results and Discussion $\quad 12$

$\begin{array}{ll}\text { Technology Transfer } & 22\end{array}$

$\begin{array}{ll}\text { Conclusions } & 22\end{array}$

Plans for Next Reporting Period $\quad 23$

References $\quad 23$ 


\section{List of Graphical Materials}

Page

Figure 1. Imbibition curves for the surfactant imbibition in oil-wet cores

Figure 2. Oil saturation at the end of imbibition experiment. Left side is the top of the core

Figure 3. Images from CT scanner at various heights at time $\mathrm{t}=0 \mathrm{hrs}$.

Figure 4. Difference in CT images at various heights at time $\mathrm{t}=120 \mathrm{hrs}$ and at $\mathrm{t}=0 \mathrm{hrs}$. It $\begin{array}{ll}\text { represents incremental water saturation at these times. } & 14\end{array}$

Figure 5. Capillary pressure curve for the core used 16

Figure 6. IFT vs the Surfactant concentration used in the numerical simulation 17

Figure 7. Current grid structure is cylindrical with axial symmetry; the one in progress is 3-D $\begin{array}{ll}\text { Cartesian with a fracture. } & 17\end{array}$

Figure 8. Experimental and numerical simulation comparison for Alf-35 system 18

Figure 9. Oil saturation at times, $\mathrm{t}=1.3,2.7,5.7,12.8,17.8,27,67,100,332$ days from top left, rowwise. $\mathrm{X}$-axis is distance from center and $\mathrm{y}$-axis is distance from bottom, $\mathrm{z}$-axis is the saturation of oil.

Figure 10. IFT at times, $\mathrm{t}=1.3,2 \cdot 7,5.7,12.8,17.8,27$ days from top left, row-wise. $\mathrm{X}$-axis is distance from center and y-axis is distance from bottom, z-axis is the IFT. System reaches low IFT of $0.001 \mathrm{mN} / \mathrm{m}$, after 17 days of imbibition

Figure 11. $\mathrm{P}_{\mathrm{c}}$ at times $\mathrm{t}=1.3,2.7,5.7,12.8,17.8,27$ days from top left, row-wise. $\mathrm{X}$-axis is distance from center and $y$-axis is distance from bottom, $\mathrm{z}$-axis is the $\mathrm{P}_{\mathrm{C}}$. System reaches $\mathrm{P}_{\mathrm{c}}=0$, after 17 days of imbibition

Figure 12. $\mathrm{C}_{\text {surfactant }}$ at times, $\mathrm{t}=1.3,2.7,5.7,12.8,17.8,27$ days from top left, row-wise. $\mathrm{X}$-axis is distance from center and y-axis is distance from bottom, z-axis is the surfactant concentration in $\mathrm{wt} \%$.

Figure 13. Scale up of the imbibition process to $1 \mathrm{~m} \times 1 \mathrm{~m}$ and $10 \mathrm{~m} \times 10 \mathrm{~m}$ fracture spacing 


\section{Executive Summary}

There are many carbonate reservoirs in US (and the world) with light oil and fracture pressure below its minimum miscibility pressure (or reservoir may be naturally fractured). Many carbonate reservoirs are naturally fractured. Waterflooding is effective in fractured reservoirs, if the formation is water-wet. Many fractured carbonate reservoirs, however, are mixed-wet and recoveries with conventional methods are low (less than 10\%). Thermal and miscible tertiary recovery techniques are not effective in these reservoirs. Surfactant flooding (or huff-n-puff) is the only hope, yet it was developed for sandstone reservoirs in the past. The goal of this research is to evaluate dilute (hence relatively inexpensive) surfactant methods for carbonate formations and identify conditions under which they can be effective. Laboratory imbibition tests show about $61 \%$ oil recovery in the case of Alf-38 and $37 \%$ in the case of DTAB. A numerical model has been developed that fits the rate of imbibition of the laboratory experiment. Field-scale fracture block simulation shows that as the fracture spacing increases, so does the time of recovery. Plans for the next quarter include simulation studies. 


\section{Introduction}

There are many carbonate reservoirs in US (and the world) with light oil and fracture pressure below its minimum miscibility pressure (or reservoir may be naturally factured). Many carbonate reservoirs are naturally fractured. Waterflooding is effective in fractured reservoirs, if the formation is water-wet. Many fractured carbonate reservoirs, however, are mixed-wet and recoveries with conventional methods are low (less than 10\%). Thermal and miscible tertiary recovery techniques are not effective in these reservoirs. Surfactant flooding (or huff-n-puff) is the only hope (Spinler et al., 2000), yet it was developed for sandstone reservoirs in the past (Bragg et al., 1982).

The goal of this research is to evaluate dilute surfactant methods for carbonate formations and identify conditions under which they can be effective. Adsorption, phase behavior, wettability alteration, IFT gradient driven imbibition, blob mobilization at high capillary and Bond numbers will be quantified. An existing laboratory simulator will be modified to incorporate the mechanisms of surfactant transport and effective parameters will be developed to model this process in a dual porosity reservoir simulator. Field-scale simulations will be conducted to identify criteria under which dilute surfactant methods are feasible without active mobility control.

This report summarizes our results for the period of January, 2005 through April, 2005.

The five tasks for the project are: (1) Adsorption, (2) Wettability alteration, (3) Gravity and viscous mobilization, (4) Imbibition, and (5) Simulation. The fourth and fifth tasks were worked on this quarter. The results of imbibition and modeling are highlighted in this report. 


\section{Experimental}

The surfactants Alfoterra 35, 38 (good wettability altering surfactants from contact angle experiments) and Alfoterra 68 (low IFT agent from phase behavior studies) were earlier used for imbibition studies. The cores were saturated with $100 \%$ field brine and then displaced with crude oil to residual water saturation $(27.5 \%)$. The cores was then aged in oil bath for a period of 18 days, to make it oil wet in nature. The cores were then used in imbibition cells filled with $0.05 \mathrm{wt}$ \% Alfoterra 35, Alfoterra 38 or Alfoterra 68 with $0.3 \mathrm{M} \mathrm{Na}_{2} \mathrm{CO}_{3}$. Another cell was used for imbibition of field brine, and another with $1 \mathrm{wt} \%$ DTAB.

Typical data obtained in the imbibition experiments include oil production from the whole core; none of the data is specific to a particular point inside the core. CT scanning is a non-invasive and rapid method which gives a 3-D visualization of the flow in a core which is otherwise not possible. Using CT scanning, we can find the requisite properties such as saturations with height and radial distance of the core. A Technicare Deltascan 2060, a fourth generation medical CT scanner is used. The fourth generation uses a fan-beam geometry of X-ray where the source rotates within a fixed ring of high efficiency detectors. During one scan, the X-ray source rotates around the sample and the X-ray attenuation at different angles is measured by 720 solid-state detectors separated at half degree intervals from each other to obtain 1-D projections. From these projections, a cross sectional slice through the sample is reconstructed by a host computer.

The uniqueness of our CT scanner is that the gantry has been rotated $90^{\circ}$ from the conventional vertical position so that the scan slice is horizontal. This enables us to conduct experiments in the vertical direction. Because of this unique feature, the effect of gravity in flow through porous media could be better understood. The sample sits on a table which can be moved vertically to 
take different slice scans, and that gives us a 3-D understanding of the process under investigation. The scanner resolution is $0.254 \times 0.254 \times 2 \mathrm{~mm}$ for each pixel. The image is a matrix of 512 x 512 pixels and the size is $512 \mathrm{~KB}$. A set of machine parameters must be selected before performing any scan. The total energy emitted by the X-ray source depends on the selection of filter, voltage, current, slice thickness and scan time. Table 1 lists the range of available and selected parameters during the course of the present study.

\begin{tabular}{|c|c|c|c|c|c|}
\hline & $\begin{array}{c}\text { Voltage } \\
(\mathrm{kV})\end{array}$ & $\begin{array}{c}\text { Current } \\
(\mathrm{mA})\end{array}$ & $\begin{array}{c}\text { Scan Time } \\
(\mathrm{sec})\end{array}$ & $\begin{array}{c}\text { Diameter } \\
(\mathrm{cm})\end{array}$ & $\begin{array}{c}\text { Thickness } \\
(\mathrm{mm})\end{array}$ \\
\hline Available & $80,100,120$ & $25,50,75,100$ & $2,4,8$ & $12,25,40,50$ & $2,5,12$ \\
\hline Selected & 120 & 75 & 8 & 12 & 2 \\
\hline
\end{tabular}

Table 1. Parameters for CT scanner.

The data acquired by each detector are analyzed by a host computer (PDP-11/34). The reconstruction of the image is done by the computer, which takes less than a minute. The binary data can be directly sent to a PC for further processing. The data needs to be converted to an ASCII file and then CT number for each pixel is calculated. The CT number represents the value of the attenuation of the X-ray beam at a certain location. The porosity of each pixel can be determined by

$$
\phi=\frac{C T_{\text {rock+brine }}-C T_{\text {rock }+ \text { air }}}{C T_{\text {brine }}-C T_{\text {air }}}
$$


where $\mathrm{CT}_{\mathrm{x}}$ is the $\mathrm{CT}$ number of the system $\mathrm{X}$. It is important to measure the $\mathrm{CT}_{\text {brine }}$ and $\mathrm{CT}_{\text {air }}$ using the imbibition cell to correct for the beam hardening effect. The CT number is calculated on the assumption that the X-ray beam is monochromatic. But in reality, the generated X-ray is polychromatic and lower energy is absorbed preferentially as the beam passes through the material. The CT numbers at edges are usually higher than those in the middle even for a perfectly homogenous material. The beam becomes harder as it passes through the sample and this effect is termed as beam hardening.

The saturation of tracer or oil for each pixel is calculated as

$$
S=\frac{C T_{\text {rock tracer }+ \text { brine }}-C T_{\text {rock }+ \text { brine }}}{\phi\left(C T_{\text {tracer }+ \text { brine }}-C T_{\text {brine }}\right)} .
$$

The program to convert the binary data to ASCII format and to compute the CT number is written in IDL. The output of this program is a $512 \times 512$ matrix of CT numbers. The programs to calculate the porosity and the saturations with time are written in MATLAB. The programs include image centering.

A dry core sample is placed inside the imbibition cell and a CT scan was done at $2 \mathrm{~mm}$ thickness and $6 \mathrm{~mm}$ separation. This gives about 25 vertical slices for the $15 \mathrm{~cm}$ core. Then the core was saturated with brine to get the CT numbers for the same sections with $100 \%$ saturated brine. Using the formula mentioned earlier, we can calculate the porosity distribution of the sample. The core aged with the reservoir oil was injected with a $20 \%$ Iododecane oil, filtered through a $5 \mu \mathrm{m}$ filter. Iododecane is used as a tracer in this study. NaI is not used as it would effect the salinity of the system and hence the surfactant behavior. The IFT and wettability alteration studies of the Iododecane oil are also conducted to see if there is any change in the behavior as 
compared to the original oil. The IFT of the Iododecane oil and normal oil with $0.3 \mathrm{M} \mathrm{Na}_{2} \mathrm{CO}_{3}$ and Alfoterra-35 system are similar, within the experimental errors. The core saturated with $72.5 \%$ oil (which has $20 \%$ Iododecane) and $27.5 \%$ field brine is surrounded by the 0.05 wt $\%$ Alfoterra 35 solution in $0.3 \mathrm{M} \mathrm{Na}_{2} \mathrm{CO}_{3}$. The scans for this system are taken regularly and the $\mathrm{CT}$ numbers are monitored. The saturation of the oil could be calculated with distance and height using the formula in the above section. 


\section{Results and Discussion}

The amount of oil recovered in the first set of imbibition experiments has reached a steady value, and these imbibition experiments have been stopped. The imbibition curves are shown in Fig 1. At this point, one of the cores was taken and cut open to visually see the distribution of the oil spatially. The images are shown in Fig 2. From Fig1, we find that with surfactant Alfoterra 38 and Alfoterra 35 we have a recovery of around $61 \%$. DTAB gives a recovery of $37 \%$. From Fig 2, we can see that the oil saturation on the top of the core is more than that at the bottom, and the center-saturation is more than the sides. This indicates a combination of both gravity driven and capillary assisted imbibition process. To better understand the mechanisms involved, additional imbibition experiments are performed inside the CT Scanner.

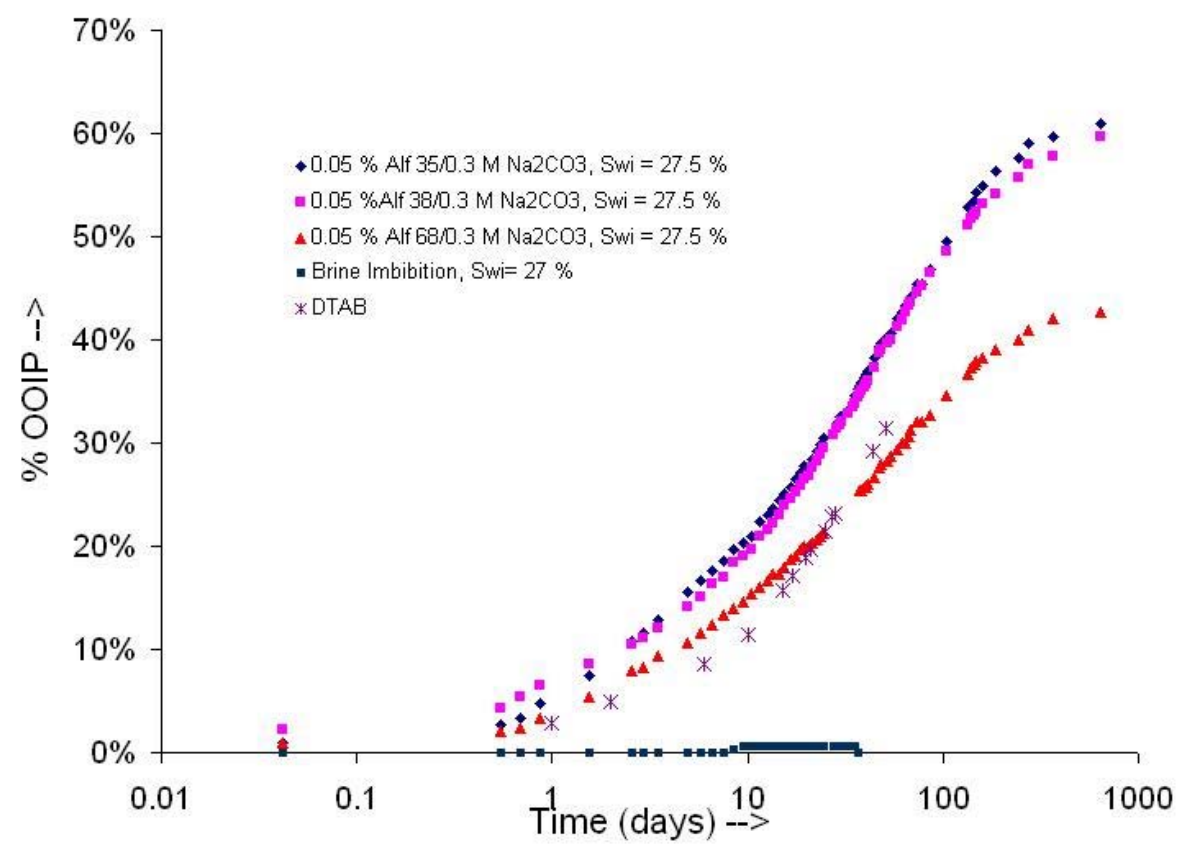

Fig. 1 - Imbibition curves for the surfactant imbibition in oil-wet cores. 


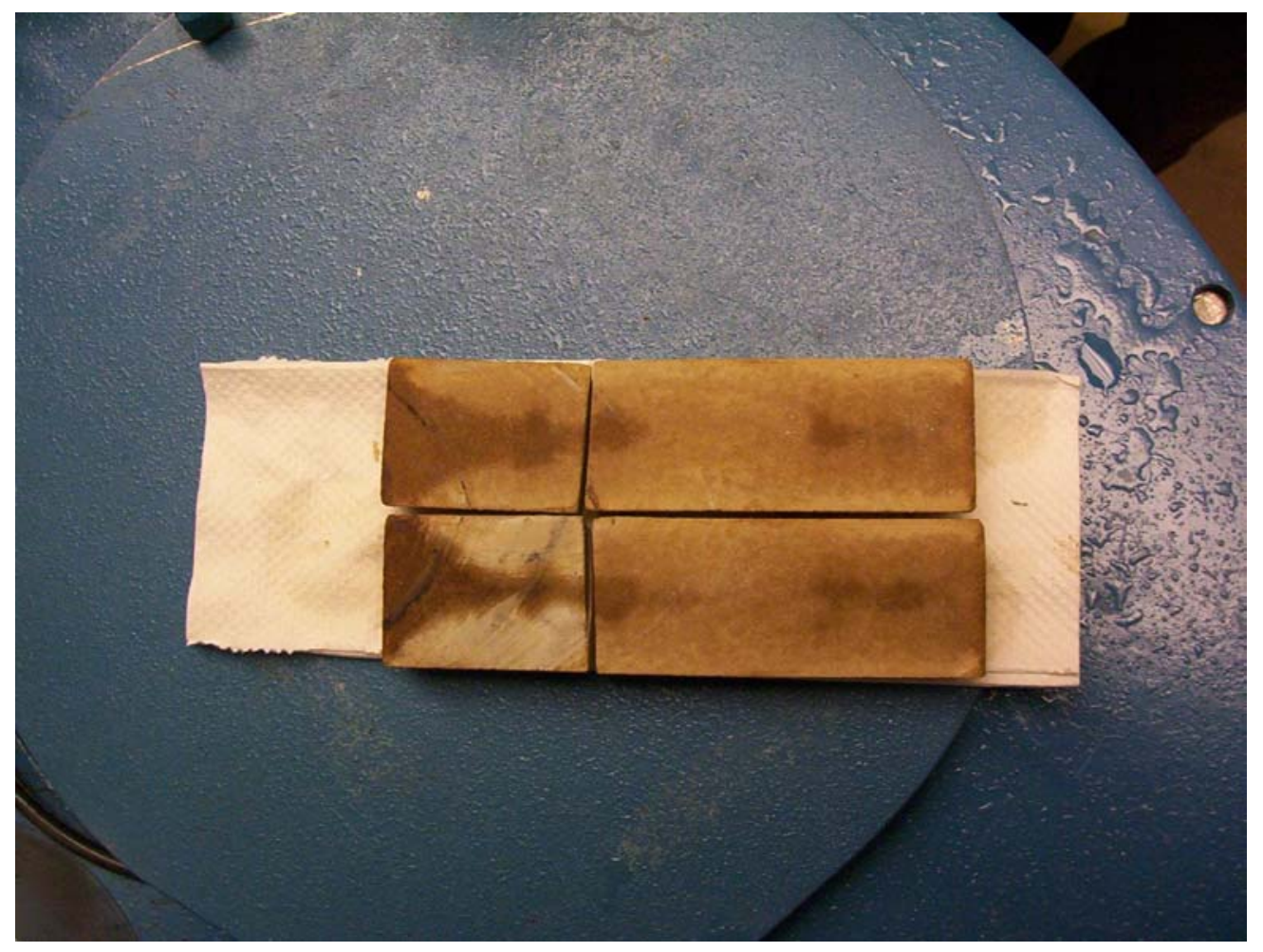

Fig. 2 - Oil saturation at the end of imbibition experiment. Left side is the top of the core.

The CT-scan images of the core at before the imbibition experiment are shown in Fig. 3 . The saturation of oil with time as calculated by the CT number is given in Fig. 4 at time $\mathrm{t}=120 \mathrm{hrs}$ during imbibition. Similar figures are currently being obtained as time of imbibition increases. It can be seen from Fig. 4, that the initial oil is driven from the sides, indicating a capillary driven mechanism initially. 


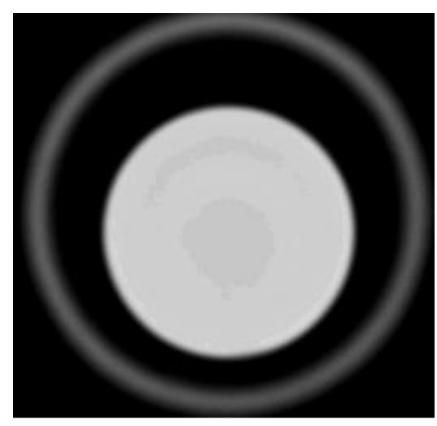

Top of the core

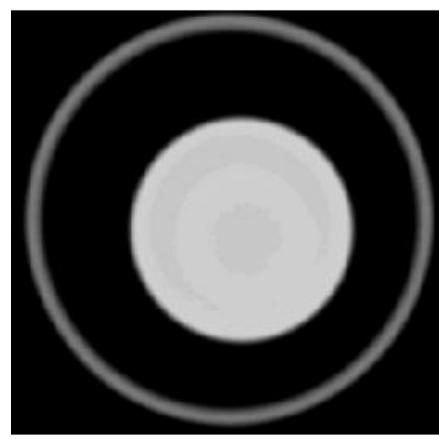

$9 \mathrm{~cm}$ from top

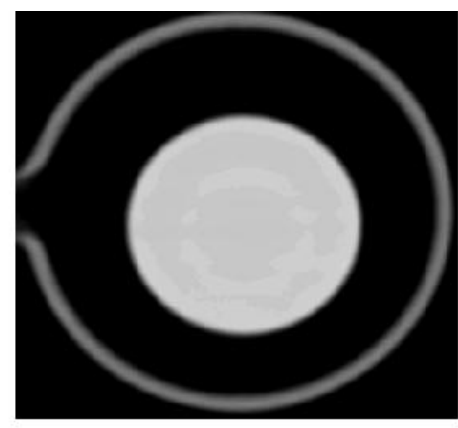

$3 \mathrm{~cm}$ from top

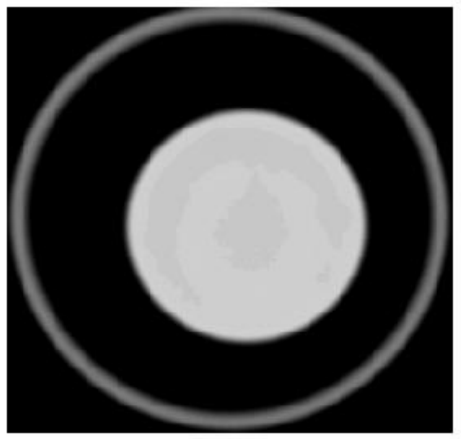

$12 \mathrm{~cm}$ from top

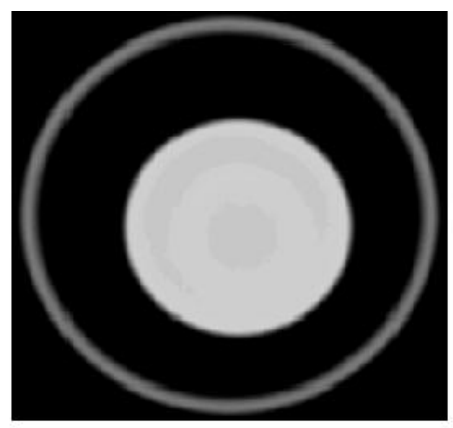

$6 \mathrm{~cm}$ from top

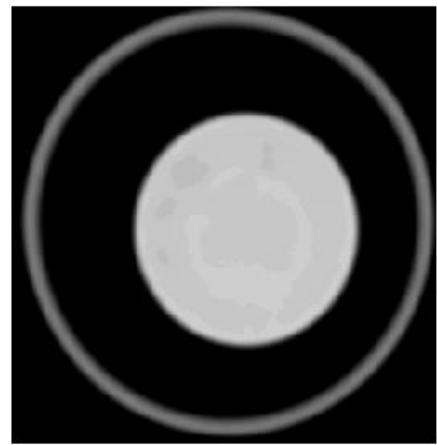

bottom of the core

Fig. 3 - Images from CT scanner at various heights at time $\mathrm{t}=0 \mathrm{hrs}$.

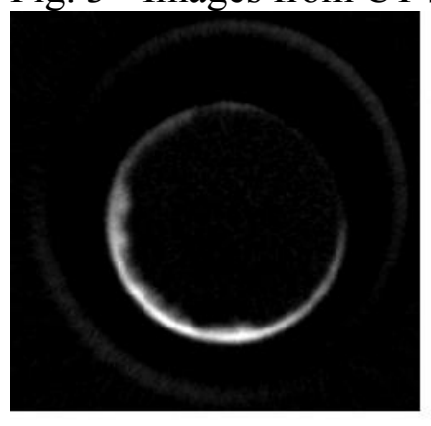

Top of the core

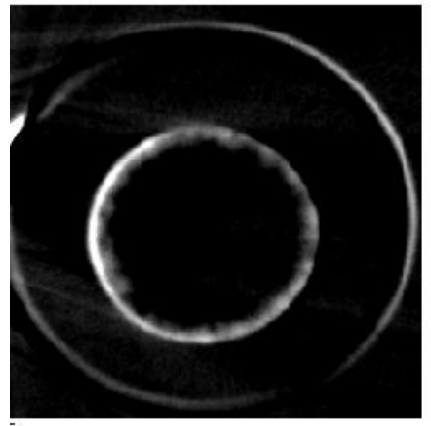

$9 \mathrm{~cm}$ from top

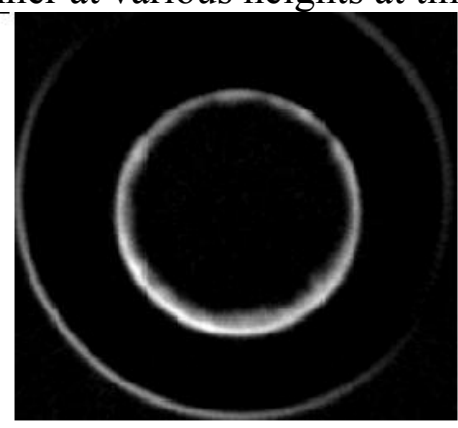

$3 \mathrm{~cm}$ from top

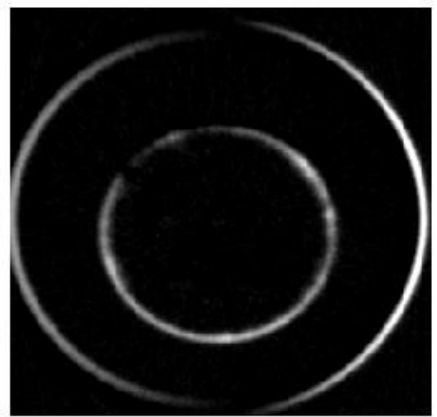

$12 \mathrm{~cm}$ from top

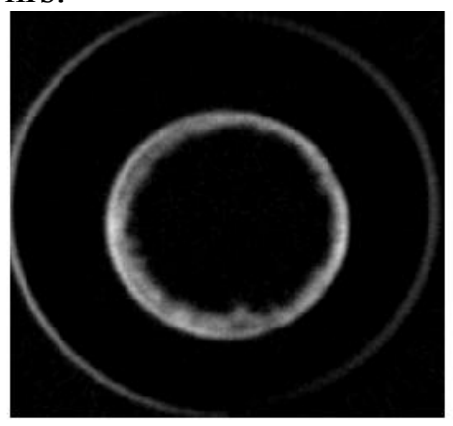

$6 \mathrm{~cm}$ from top

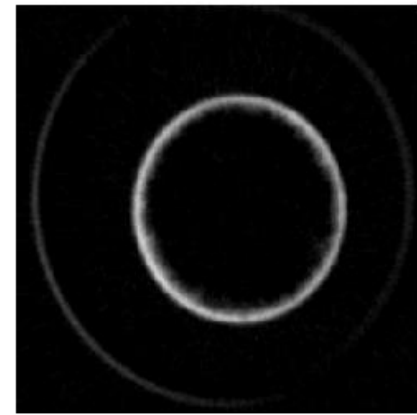

bottom of the core

Fig. 4 - Difference in CT images at various heights at time $\mathrm{t}=120 \mathrm{hrs}$ and at $\mathrm{t}=0 \mathrm{hrs}$. It represents incremental water saturation at these times. 
In order to better understand the process of oil recovery from an oil wet matrix block using surfactant flooding, a numerical model of the system is developed to simulate the process. For an oil-wet reservoir, introduction of surfactant into the brine phase can improve oil production by lowering the interfacial tension (IFT) between the oil phase and brine phase and by altering the wettability of the rock to water-wet. The effects of surfactant on oil production from fractured oil-wet reservoir during counter-current imbibition are studied with a 3-D numerical simulator. The capillary pressure between oil and brine and the relative permeability and residual saturation of both phases are considered as functions of IFT between oil and brine and the wettability of rock, which are correlated to the surfactant and salt concentrations with the data obtained from laboratory experiments. The mass balance equations are solved with a fully implicit scheme.

Laboratory scale simulation results match the experimental results very well. Simulation results indicate that both capillarity and gravity help to improve oil production: in the early stage of the production, capillarity is found to be the major driving force, and in the late stage, gravity dominates the production behavior. In the last report, the general effect of various parameters such as the IFT, wettability, entry capillary pressure was shown. In this study, we tried varying the parameters and matching the experimental data. A mercury capillary pressure curve was obtained for the carbonate sample; the capillary pressure is shown in Fig. 5. It could be seen that the carbonate core is not completely homogeneous and has distribution of pores. This capillary pressure curve was modified for secondary drainage and imbibition and was used in the model. The IFT was varied with the surfactant concentration by performing a fit on the experimental data obtained for different surfactant concentrations at $0.3 \mathrm{M} \mathrm{Na}_{2} \mathrm{CO}_{3}$. The same behavior was used for the present WOR. Here, we assumed that the salt diffusion is much faster as compared to the surfactant diffusion in water; hence the salt concentration is $0.3 \mathrm{M} \mathrm{Na}_{2} \mathrm{CO}_{3}$ and the IFT 
varies with only the surfactant concentration. The salt diffusion could be taken into account in the model, but it would lead to higher computation times. Also, the behavior of the IFT with salt concentration at various surfactant concentrations needs to be experimentally investigated. This work is under progress. The IFT variation with the surfactant concentration is plotted in Fig. 6.

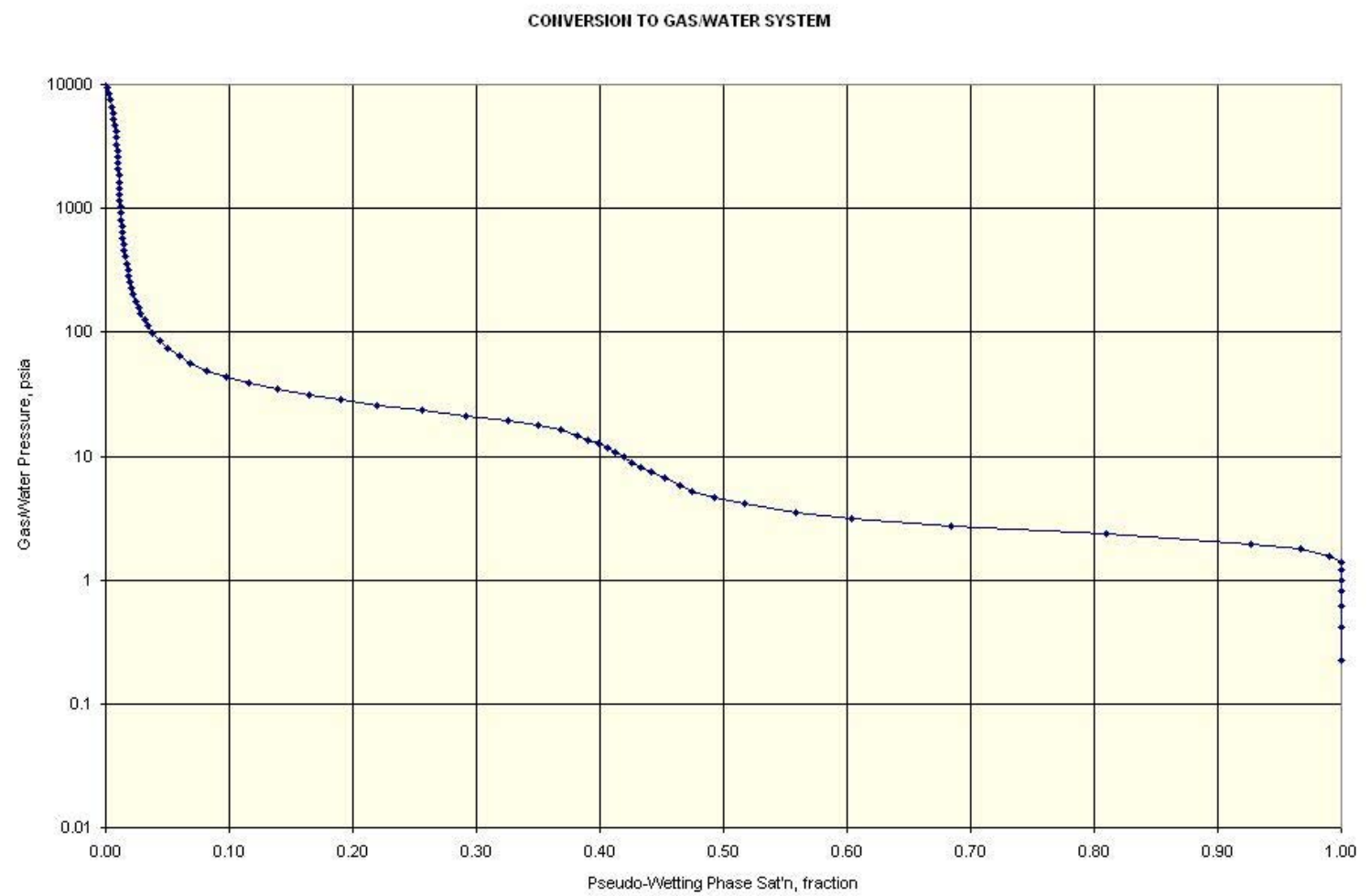

Fig. 5 - Capillary pressure curve for the core used.

Wettability also varies with the surfactant concentration; this is taken as a ramp function from initial wettability to final wettability in the model. Experimentally, we know that the initial wettability is oil-wet, and the initial contact angle is taken by measure the contact angle of water droplet placed on top of the core. A more thorough wettability index needs to be used for quantifying the initial wettability of the system. The final wettability of the core is a parameter which is determined by matching the experimental curve with the numerical simulator. The time of simulation on a $1 \mathrm{~GB}$ RAMS, 1.6 MHz processor for a lab simulator is 240 mins, and for $10 \mathrm{mX} 10 \mathrm{~m}$ field-scale simulation is 6 days. The number of grid blocks used is $10 \mathrm{x} 40$, with 
radial symmetry. The code is also run in a unix machine where the simulations are at least 4 times faster. The grid structure is being modified to include 3-D Cartesian coordinate system and also inclusion of fracture. The current grid structures are given in Fig. 7.

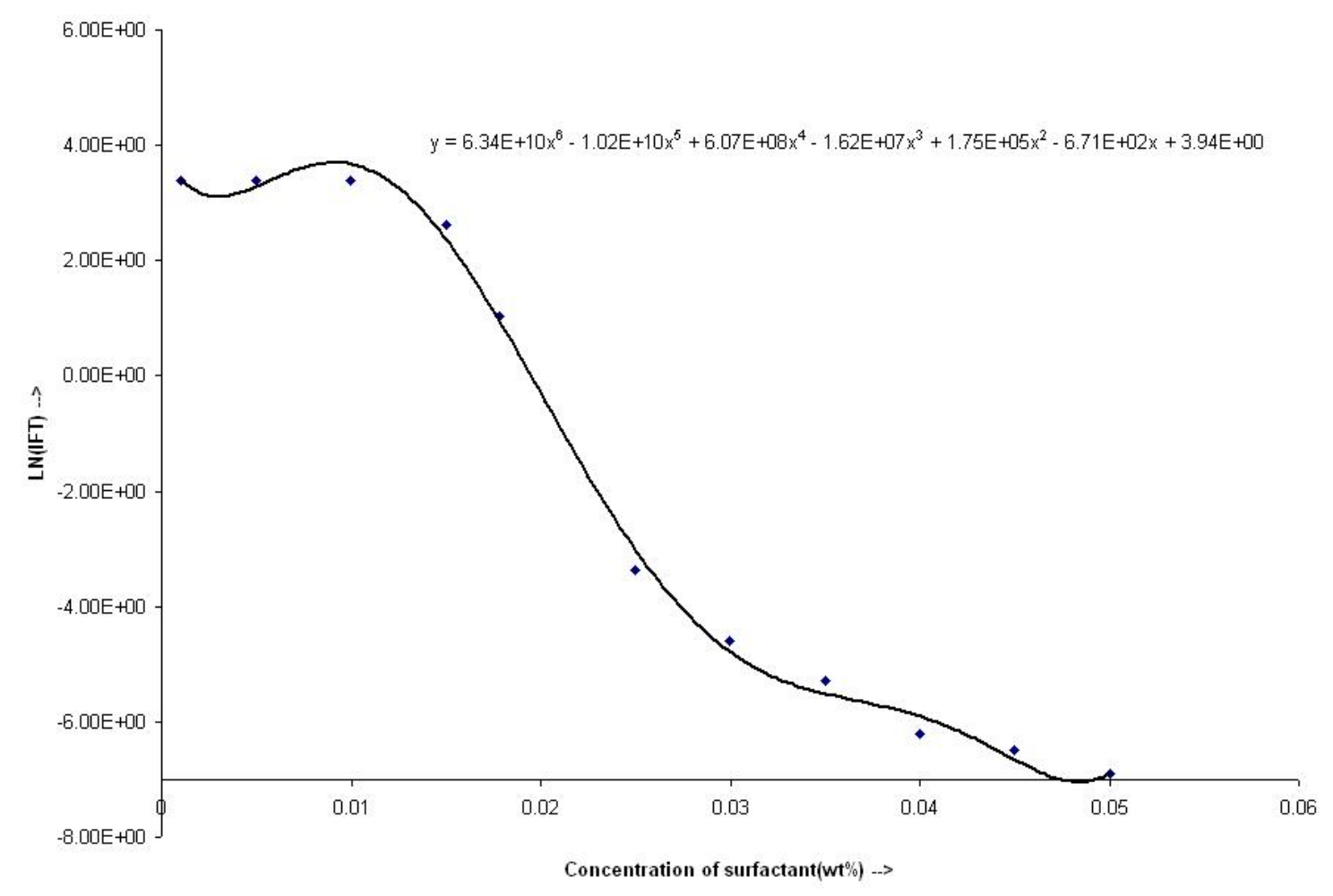

Fig. 6 - IFT vs the Surfactant concentration used in the numerical simulation

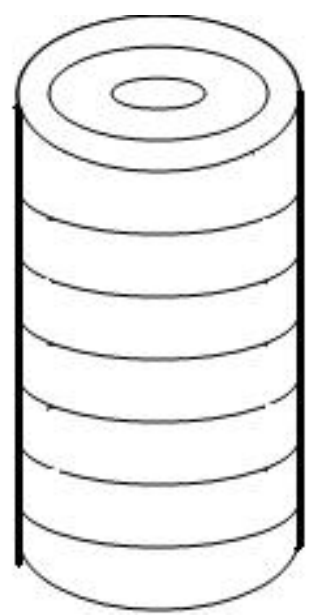

$s$

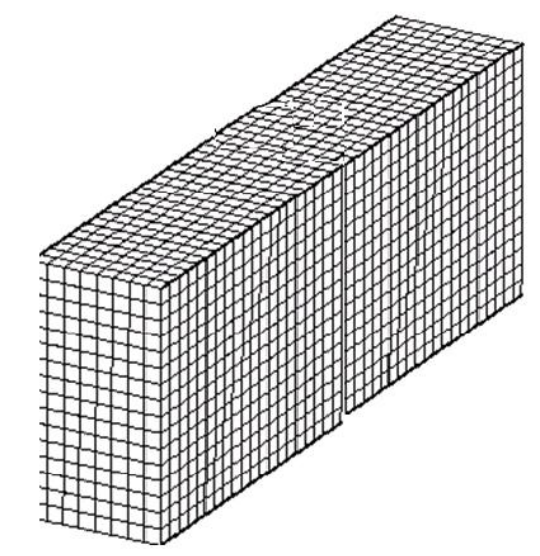

Fig. 7 - Current grid structure is cylindrical with axial symmetry; the one in progress is 3-D Cartesian with a fracture. 


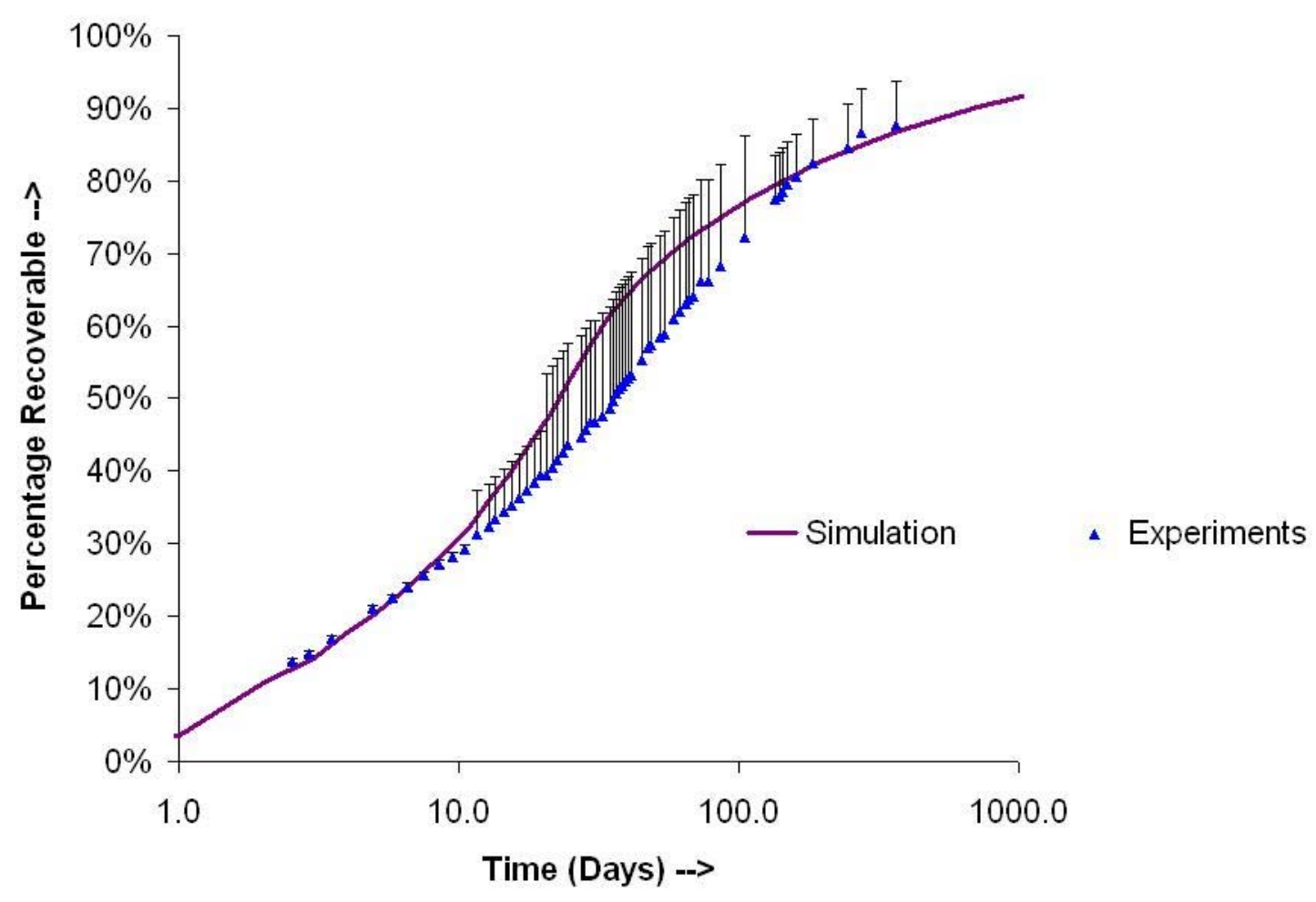

Fig. 8 - Experimental and numerical simulation comparison for Alf-35 system

The experimental data and numerical simulation results are shown in Fig. 8. The experimental values are the volume of coalesced oil collected at the top of the cell. In addition to that oil, there is a certain amount of oil in the macro-emulsion form in the surfactant solution surrounding and above the core. A simple calculation estimates this amount to be around $2 \mathrm{ml}$, which results in the error bars in the experimental values in Fig. 8. Thus, there is a good match between the experimental data and simulation results. The simulation of the oil production from the lab-scale core also generates the saturation profile and various other parameters like IFT, contact angle, capillary pressure, etc. at various locations. The movie files for the oil saturation, water saturation, surfactant concentration, IFT and contact angle could not be attached with the report. Snap shots of the oil saturation at various time is given in Fig. 9. IFT at these times are given in Fig. 10. $\mathrm{P}_{\mathrm{C}}$ is given in Fig. 11 and surfactant weight fraction is given in Fig. 12. 

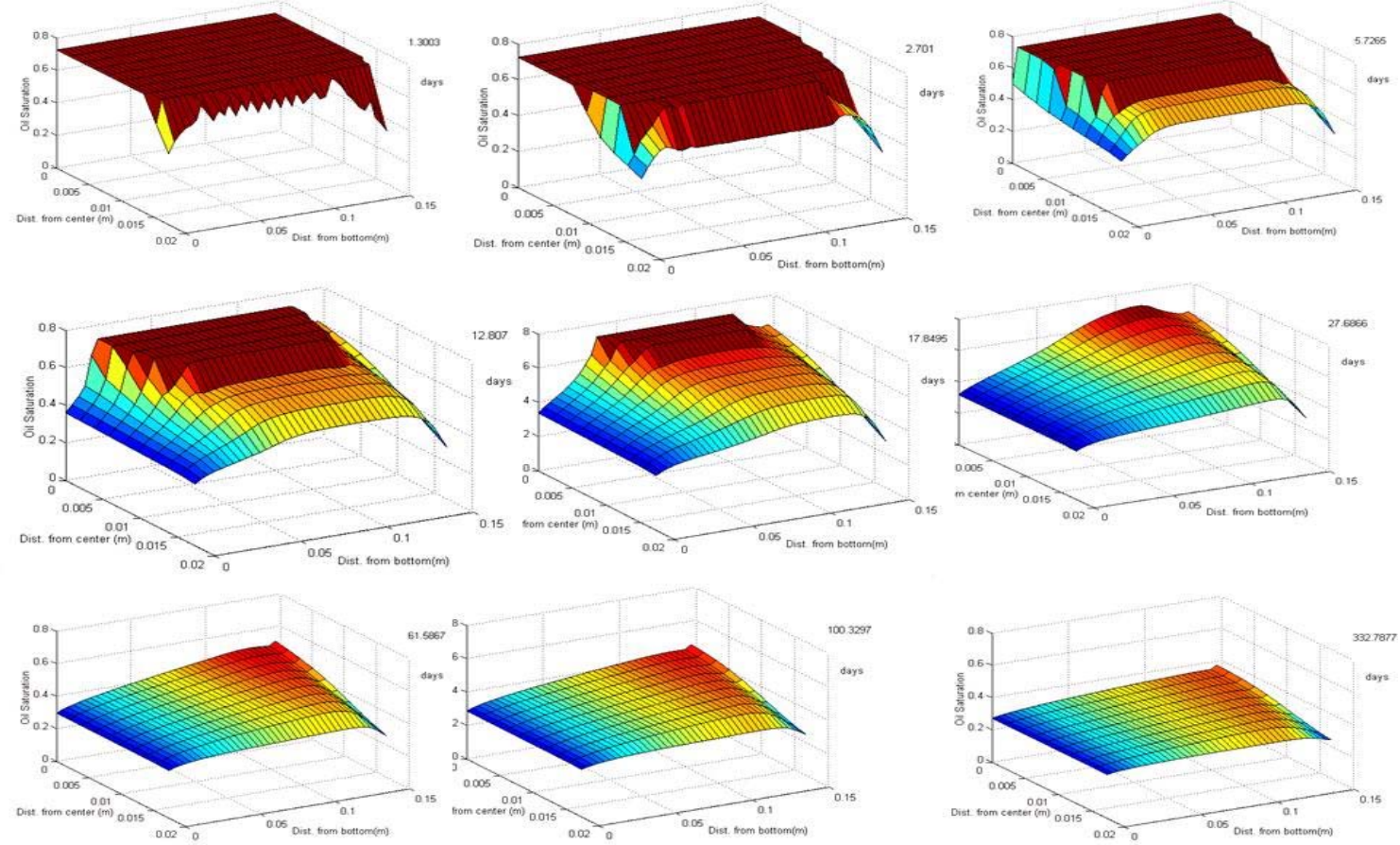

Fig. 9 - Oil saturation at times, $\mathrm{t}=1.3,2.7,5.7,12.8,17.8,27,67,100,332$ days from top left, rowwise. $\mathrm{X}$-axis is distance from center and $\mathrm{y}$-axis is distance from bottom, $\mathrm{z}$-axis is the saturation of oil.
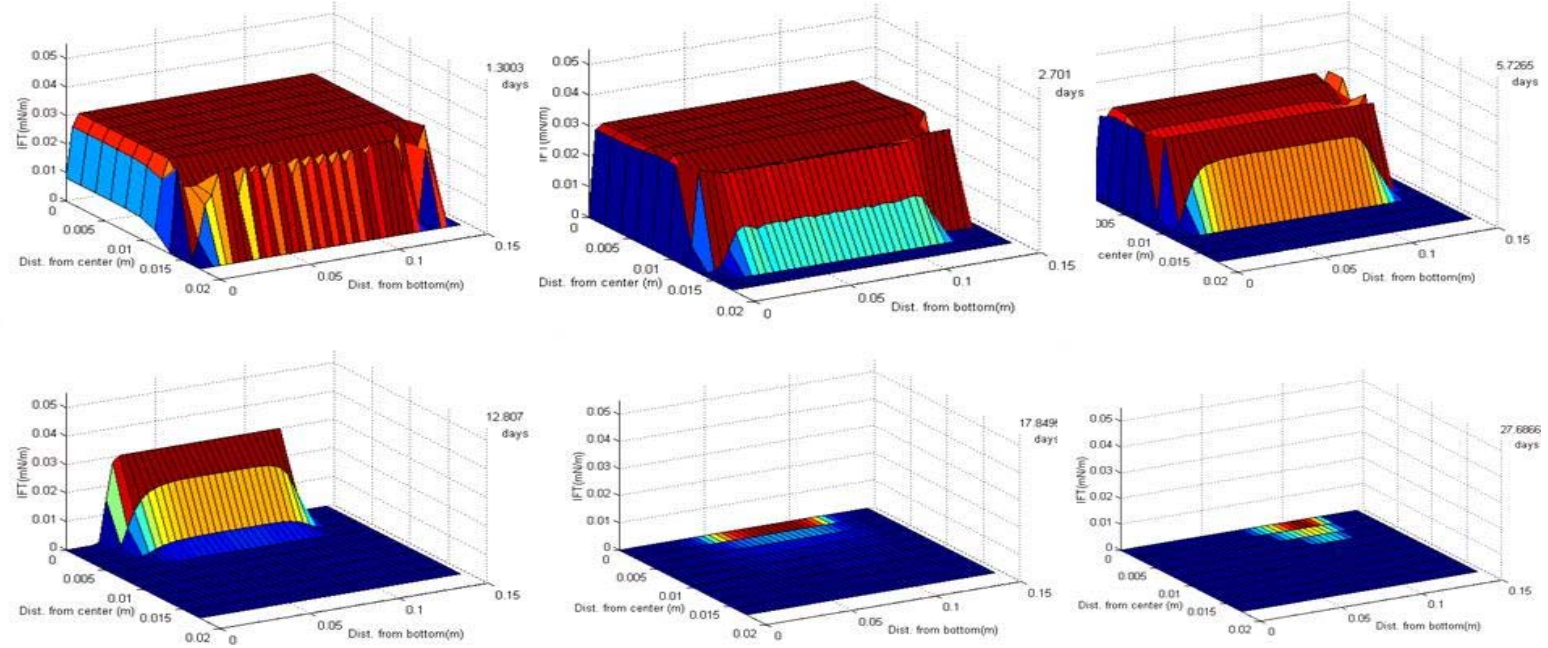

Fig. 10 - IFT at times, $\mathrm{t}=1.3,2.7,5.7,12.8,17.8,27$ days from top left, row-wise. $\mathrm{X}$-axis is distance from center and y-axis is distance from bottom, z-axis is the IFT. System reaches low IFT of $0.001 \mathrm{mN} / \mathrm{m}$, after 17 days of imbibition. 
It can be seen from Figs. 10-12 that the system reaches the steady IFT value $0.001 \mathrm{mN} / \mathrm{m}$, contact angle of $75^{\circ}$ and essentially zero capillary pressure (because of low IFT). This is because surfactant diffuses and reaches bulk value by the time of 17 days.
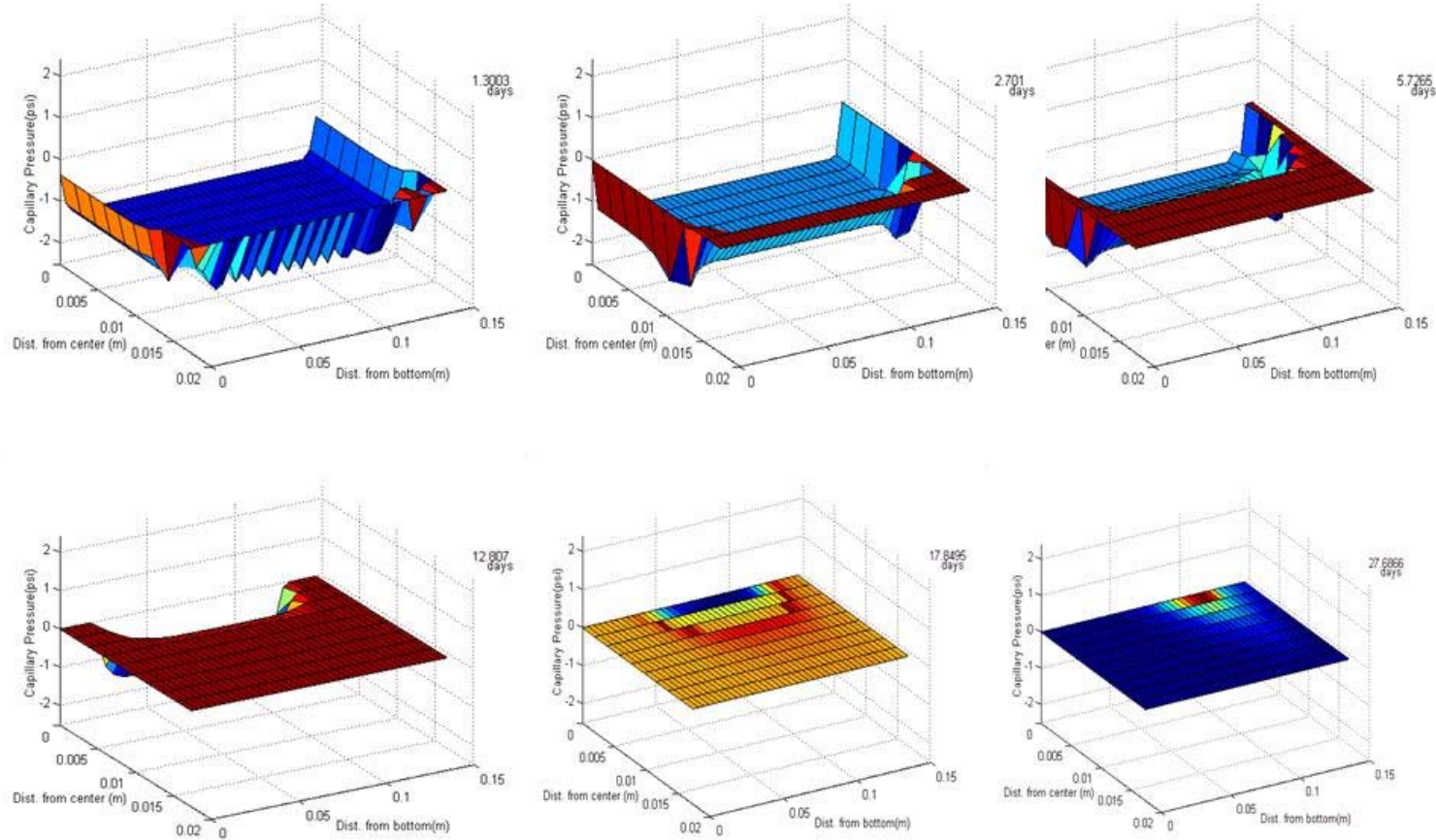

Fig. $11-\mathrm{P}_{\mathrm{c}}$ at times $\mathrm{t}=1.3,2.7,5.7,12.8,17.8,27$ days from top left, row-wise. $\mathrm{X}$-axis is distance from center and $y$-axis is distance from bottom, $\mathrm{z}$-axis is the $\mathrm{P}_{\mathrm{C}}$. System reaches $\mathrm{P}_{\mathrm{c}}=0$, after 17 days of imbibition. 

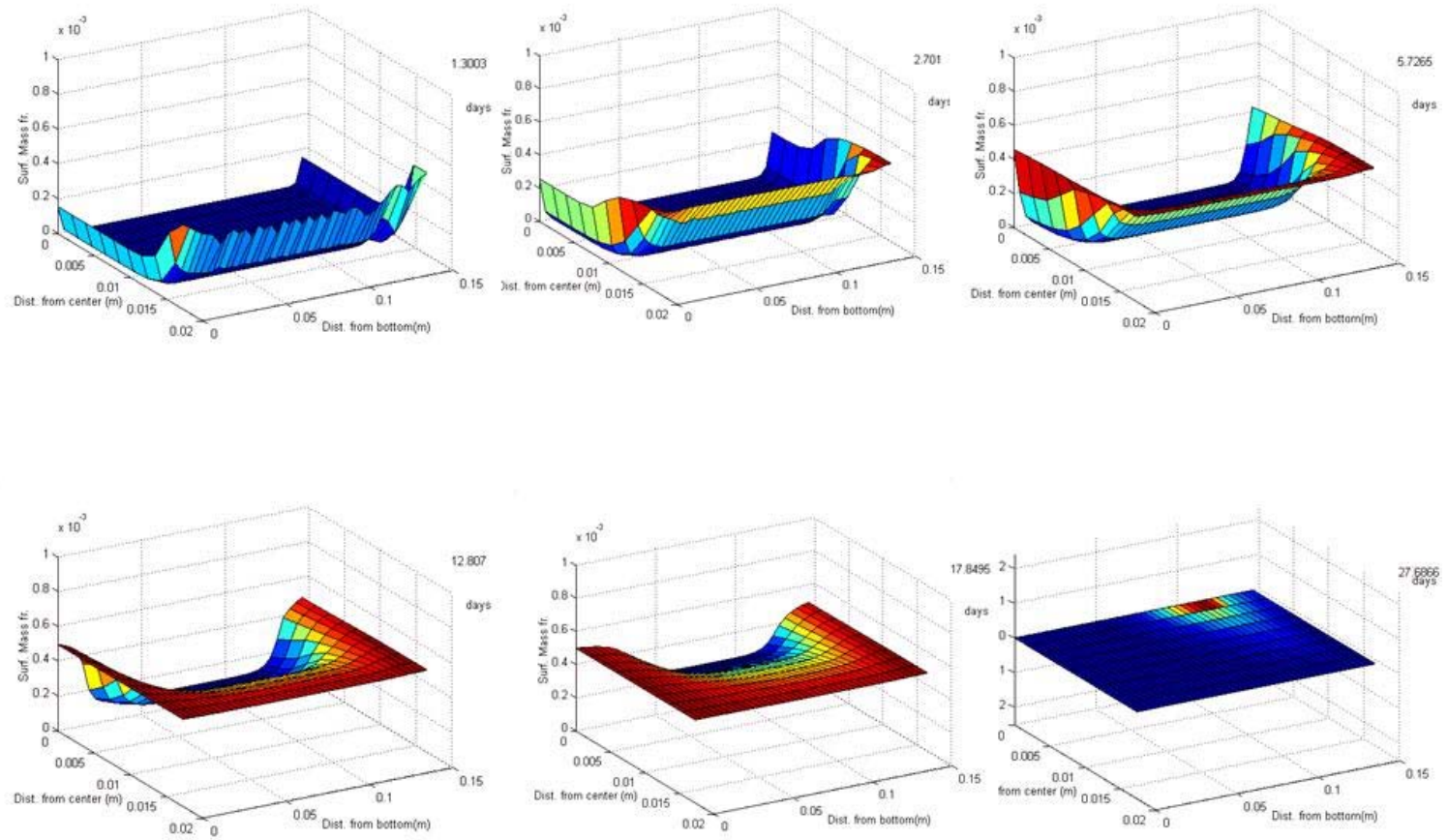

Fig. $12-\mathrm{C}_{\text {surfactant }}$ at times, $\mathrm{t}=1.3,2.7,5.7,12.8,17.8,27$ days from top left, row-wise. $\mathrm{X}$-axis is distance from center and $\mathrm{y}$-axis is distance from bottom, $\mathrm{z}$-axis is the surfactant concentration in $\mathrm{wt} \%$. System reaches low IFT of $0.001 \mathrm{mN} / \mathrm{m}$, after 17 days of imbibition.

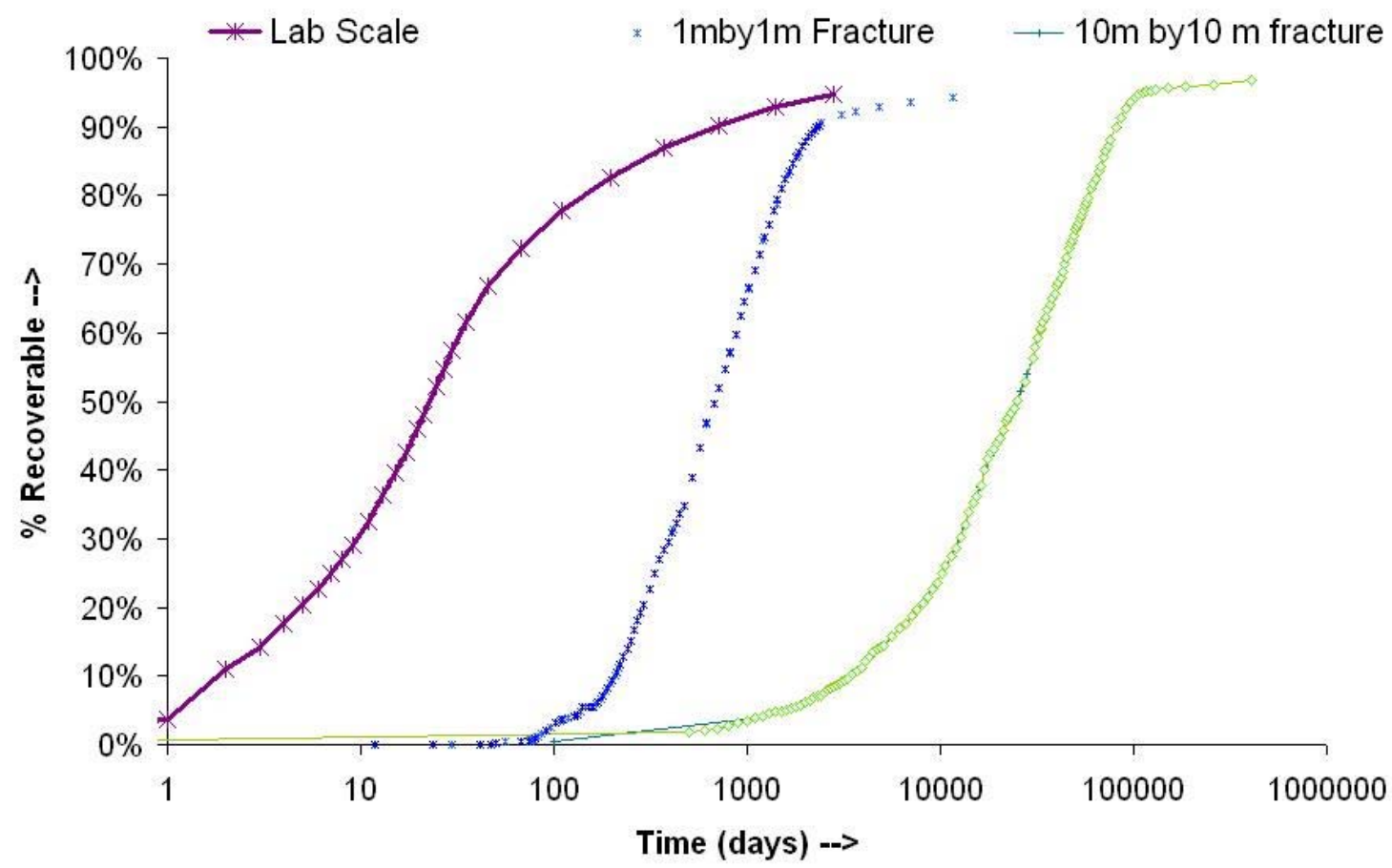

Fig. 13 - Scale up of the imbibition process to $1 \mathrm{~m} \times 1 \mathrm{~m}$ and $10 \mathrm{~m} \times 10 \mathrm{~m}$ fracture spacing. 
This numerical simulator is also used to simulate field-scale fracture blocks of $1 \mathrm{~m} \mathrm{X} 1 \mathrm{~m}$ and $10 \mathrm{~m}$ X10 m. The expected recovery from such a system is shown in Fig. 13. The initial imbibition is controlled by capillarity, but the majority of the recovery is controlled by gravity drainage. The fracture spacing controls the recovery rate. If the fracture spacing is of the order of meters, then most of the oil is recovered within ten years. If the fracture spacing is 10 meters, the recovery time is about 300 years, for the parameters used in this study. We are continuing the sensitivity study of this process to key parameters.

\section{Technology Transfer}

We have written an abstract, SPE 93009, for presentation in Fall 2005.

\section{Conclusions}

Anionic surfactants (Alfoterra 35, 38) recover about $61 \%$ of the oil in about 300 days by imbibition driven by wettability alteration and gravity in the core-scale. The recovery in the DTAB system was much lower, $\sim 37 \%$. CT scanning of the imbibition experiment shows that the initial recovery is capillarity-driven where as later recovery is gravity-driven (Task 4). The simulation result matches the laboratory imbibition experimental data. Scale-up of the method indicates that the fracture spacing controls the rate of recovery. For the parameters assumed, most of the oil was recovered in 10 years for one meter fracture spacing (Task 5). The anionic surfactants look promising but field-scale experiments need to be conducted to better evaluate the surfactant methods for fractured media. 


\section{Plans for Next Reporting Period}

- Imbibition experiments (Task 4)

- Simulation (Task 5)

\section{References}

Bragg, J. R. et al.: "Loudon Surfactant Flood Pilot Test," SPE/DOE 10862, SPE/DOE $3^{\text {rd }}$ Joint Symposium on EOR, Tulsa, April 4-7, 1982.

Spinler, E. A. et al.: "Enhancement of Oil Recovery Using Low Concentration Surfactant to Improve Spontaneous or Forced Imbibition in Chalk," SPE 59290, SPE/DOE Improved Oil Recovery Symposium, Tulsa, April 3-5, 2000. 